\title{
Ultra-thin occlusal veneers bonded to enamel and made of ceramic or hybrid materials exhibit load-bearing capacities not different from conventional restorations
}

\author{
Ioannidis, Alexis ; Mühlemann, Sven ; Özcan, Mutlu ; Hüsler, Jürg ; Hämmerle, Christoph H F ; Benic, \\ Goran I
}

\begin{abstract}
OBJECTIVES The objective of this study was to test whether or not the load-bearing capacity of occlusal veneers bonded to enamel and made of ceramic or hybrid materials does differ from those of porcelain-fused-to-metal or lithium disilicate glass ceramic crowns. MATERIAL AND METHODS In 80 human molars occlusal enamel was removed without extending into the dentin in order to mimic substance defects caused by attrition. The restorations were digitally designed at a standardized thickness of either $0.5 \mathrm{~mm}$ or $1.0 \mathrm{~mm}$. For each thickness, 4 test groups were formed each including a different restorative material: "0.5-ZIR": $0.5 \mathrm{~mm}$ thick zirconia (Vita YZ HT); "1.0-ZIR": $1.0 \mathrm{~mm}$ thick zirconia (Vita YZ HT); "0.5-LDC": $0.5 \mathrm{~mm}$ thick lithium disilicate ceramic (IPS e.max Press); "1.0-LDC": $1.0 \mathrm{~mm}$ thick lithium disilicate ceramic (IPS e.max Press); "0.5-HYC": $0.5 \mathrm{~mm}$ thick PICN (Vita Enamic); "1.0HYC": $1.0 \mathrm{~mm}$ thick PICN (Vita Enamic); "0.5-COC": $0.5 \mathrm{~mm}$ thick tooth shaded resin composite (Lava Ultimate) and "1.0-COC": $1.0 \mathrm{~mm}$ thick tooth shaded resin composite (Lava ultimate). Each group consists of 10 specimens. Two additional groups of 10 specimens each were used as controls and exhibited conventional crown preparations. In one group the crowns were made of lithium-disilicate ceramic ("CLD": IPS e.max CAD) and the other group consisted of porcelain-fused to metal crowns ("PFM"). All restorations were cemented onto the prepared teeth following the manufacturer's instruction of the corresponding luting cement. Subsequently, they were thermo-mechanically aged and then loaded until fracture. Load-bearing capacities (F) between the groups were compared applying the KruskalWallis test $(\mathrm{p}<0.05)$ and pairwise group comparisons using the Dunn's method. RESULTS Median values (and quartiles) for the load-bearing capacity amounted to (F) 2'407 (1'670; 2'490) N for the CLD group and to 2'033 (1'869; 2'445) $\mathrm{N}$ for the PFM group. For the $0.5 \mathrm{~mm}$ thick restorations F reached the highest median value in group 0.5-HYC 2'390 (1'355; 2'490) N, followed by 0.5-COC 2'200 (1'217; 2 '492) N and 0.5-LDC 1'692 (1'324; 2'355) N. No results were obtained for group 0.5-ZIR due to the impracticability to fabricate ultra-thin specimens. The distribution of the values for the $1.0 \mathrm{~mm}$ thick restorations was 2'489 (2'426; 2'491) $\mathrm{N}$ for 1.0-COC, 2'299 (2'156; 2'490) N for 1.0-ZIR, 2'124 (1'245; 2'491) N for 1.0-HYC, and 1'537 (1'245; 1'783) N for 1.0-LDC. The differences of the medians between the test and the control groups did not reach statistical significance for the $0.5 \mathrm{~mm}$ thick specimens $(\mathrm{KW}: \mathrm{p}$ $=0.6952$ and $\mathrm{p}=0.6986)$. Within the groups exhibiting $1.0 \mathrm{~mm}$ thickness, however, significant different medians were found: 1.0-LDC $<1.0-\mathrm{ZIR}$ and 1.0-LDC $<1.0-\mathrm{COC}(\mathrm{KW}: \mathrm{p}<0.0209)$. CONCLUSIONS Regarding their maximum load-bearing capacity, minimally invasive occlusal veneers made of ceramic and hybrid materials can be applied to correct occlusal tooth wear and thus replace conventional crown restorations.
\end{abstract}

DOI: https://doi.org/10.1016/j.jmbbm.2018.09.041 
ZORA URL: https://doi.org/10.5167/uzh-159417

Journal Article

Accepted Version

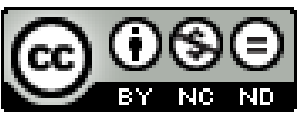

The following work is licensed under a Creative Commons: Attribution-NonCommercial-NoDerivatives 4.0 International (CC BY-NC-ND 4.0) License.

Originally published at:

Ioannidis, Alexis; Mühlemann, Sven; Özcan, Mutlu; Hüsler, Jürg; Hämmerle, Christoph H F; Benic, Goran I (2018). Ultra-thin occlusal veneers bonded to enamel and made of ceramic or hybrid materials exhibit load-bearing capacities not different from conventional restorations. Journal of the Mechanical Behavior of Biomedical Materials, 90:433-440.

DOI: https://doi.org/10.1016/j.jmbbm.2018.09.041 


\section{Ultra-thin occlusal veneers bonded to enamel and made of ceramic or hybrid materials exhibit load-bearing capacities not different from conventional restorations}

Alexis Ioannidis ${ }^{a}$, Sven Mühlemann ${ }^{a}$, Mutlu Özcan ${ }^{a}$, Jürg Hüsler ${ }^{b}$, Christoph HF Hämmerle $^{a}$, Goran I Benic $^{a}$

Key words: ceramics, hybrid material, dental porcelain, resins, computer-aided design, computeraided manufacturing, occlusal dental veneers, fatigue

Address for correspondence:

Dr. med. dent. Alexis loannidis

Clinic of Fixed and Removable Prosthodontics and

Dental Material Science

Center of Dental Medicine, University of Zurich

Plattenstrasse 11

$\mathrm{CH}-8032$ Zurich, Switzerland

Phone: +41446340404

Fax: +41446344305

e-mail: alexis.ioannidis@zzm.uzh.ch

a Clinic of Fixed and Removable Prosthodontics and Dental Material Science, Center of Dental Medicine, University of Zurich, Switzerland

${ }^{\mathrm{b}}$ Department of Mathematical Statistics, University of Bern, Switzerland 


\section{Abstract}

Objectives: The objective of this study was to test whether or not the load-bearing capacity of occlusal veneers bonded to enamel and made of ceramic or hybrid materials does differ from those of porcelainfused-to-metal or lithium disilicate glass ceramic crowns.

Material and methods: In 80 human molars occlusal enamel was removed without extending into the dentin in order to mimic substance defects caused by attrition. The restorations were digitally designed at a standardized thickness of either $0.5 \mathrm{~mm}$ or $1.0 \mathrm{~mm}$. For each thickness, 4 test groups were formed each including a different restorative material: "0.5-ZIR": $0.5 \mathrm{~mm}$ thick zirconia (Vita YZ HT); "1.0-ZIR": $1.0 \mathrm{~mm}$ thick zirconia (Vita YZ HT); "0.5-LDC": $0.5 \mathrm{~mm}$ thick lithium disilicate ceramic (IPS e.max Press); "1.0-LDC": $1.0 \mathrm{~mm}$ thick lithium disilicate ceramic (IPS e.max Press); "0.5-HYC": $0.5 \mathrm{~mm}$ thick PICN (Vita Enamic); "1.0-HYC": $1.0 \mathrm{~mm}$ thick PICN (Vita Enamic); "0.5-COC": $0.5 \mathrm{~mm}$ thick tooth shaded resin composite (Lava Ultimate) and "1.0-COC": $1.0 \mathrm{~mm}$ thick tooth shaded resin composite (Lava ultimate). Each group consists of 10 specimens. Two additional groups of 10 specimens each were used as controls and exhibited conventional crown preparations. In one group the crowns were made of lithium-disilicate ceramic (“CLD”: IPS e.max CAD) and the other group consisted of porcelainfused to metal crowns ("PFM"). All restorations were cemented onto the prepared teeth following the manufacturer's instruction of the corresponding luting cement. Subsequently, they were thermomechanically aged and then loaded until fracture. Load-bearing capacities $\left(F_{\max }\right)$ between the groups were compared applying the Kruskal-Wallis test $(p<0.05)$ and pairwise group comparisons using the Dunn's method.

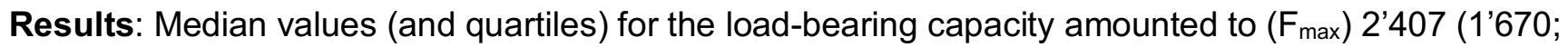
2'490) $\mathrm{N}$ for the CLD group and to 2'033 (1'869; 2'445) $\mathrm{N}$ for the PFM group. For the $0.5 \mathrm{~mm}$ thick restorations $\mathrm{F}_{\max }$ reached the highest median value in group 0.5-HYC 2'390 (1'355; 2'490) N, followed by $0.5-C O C$ 2'200 (1'217; 2'492) N and 0.5-LDC 1'692 (1'324; 2'355) N. No results were obtained for group $0.5-$ ZIR due to the impracticability to fabricate ultra-thin specimens. The distribution of the values for the $1.0 \mathrm{~mm}$ thick restorations was 2'489 (2'426; 2'491) $\mathrm{N}$ for 1.0-COC, 2'299 (2'156; 2'490) $\mathrm{N}$ for 1.0-ZIR, 2'124 (1'245; 2'491) N for 1.0-HYC, and 1'537 (1'245; 1'783) N for 1.0-LDC. The differences 
of the medians between the test and the control groups did not reach statistical significance for the 0.5 $\mathrm{mm}$ thick specimens $(\mathrm{KW}: \mathrm{p}=0.6952$ and $\mathrm{p}=0.6986)$. Within the groups exhibiting $1.0 \mathrm{~mm}$ thickness, however, significant different medians were found: 1.0-LDC < 1.0-ZIR and 1.0-LDC < 1.0-COC (KW: $p$ $<0.0209)$.

Conclusions: Regarding their maximum load-bearing capacity, minimally invasive occlusal veneers made of ceramic and hybrid materials can be applied to correct occlusal tooth wear and thus replace conventional crown restorations. 


\section{Introduction}

Several causes can lead to loss of tooth substance (Smith and Knight, 1984). The etiology include carious, erosive, abrasive and/or attritive processes (Smith and Knight, 1984). Clinically, tooth wear can have effects such as pulpal complications, loss of vertical dimension, esthetic and functional impairments (Dietschi and Argente, 2011; Loomans et al., 2017). Preparation design for traditional crowns require the removal of substantial amounts of coronal enamel and dentin (Edelhoff and Sorensen, 2002a, b). In cases of erosion, abrasion or attrition, a substantial amount of coronary tooth structure is missing. Hence, it makes sense to apply strategies for reconstructing the hampered dentition that conserve the remaining tooth substance as much as possible. It has been suggested that ultra-thin occlusal veneers represent an option to traditional treatment concepts with circular crown preparation (Muts et al., 2014). The treatment concept applying ultra-thin occlusal onlays aims at replacing the lost tooth substance without the additional removal of remaining tooth substance (Edelhoff and Sorensen, 2002a, $\underline{b}$ ).

When applied clinically the brittleness and fragility of traditional feldspathic materials requires them to be applied with an occlusal thickness of at least $2 \mathrm{~mm}$ (Guess et al., 2013). This thickness is often greater than the clinically needed thickness and thus requires additional removal of tooth substance. In order to allow for minimally invasive preparations new materials have been introduced demonstrating enhanced physical properties (Denry and Kelly, 2008; Guazzato et al., 2004a, $\underline{\text { b) }}$. One group consists of glass ceramics containing lithium disilicate ceramic particles (Guazzato et al., 2004a). Another group is comprised by zirconia ceramics (Denry and Kelly, 2008). Both materials exhibit higher flexural strength and improved fracture toughness compared to conventional feldspathic ceramics (Christel et al., 1989; Elsaka and Elnaghy, 2016; Guazzato et al., 2004b; Miyazaki et al., 2013; Swain et al., 2016; Wagner and Chu, 1996). An additional approach to optimize the mechanical properties is to combine the benefits of ceramic and polymer materials. Along these lines new materials were recently introduced either consisting of a polymer-infiltrated ceramic-network (PICN), the so-called hybrid ceramics (Awada and Nathanson, 2015; Swain et al., 2016) or tooth shaded resin composite materials for indirect applications, where the latter typically consists of nanoparticle- and nanocluster-filled resin 
(Awada and Nathanson, 2015). The rationale behind combining resin and ceramic materials is to take advantage of the elastic deformation properties of these materials and thus increase their tolerance to loading forces (Awada and Nathanson, 2015).

The objective of this study was to test whether or not the load-bearing capacity of occlusal veneers made of ceramic or hybrid materials does not differ from those of porcelain-fused-to metal or lithium disilicate glass ceramic crowns. The hypothesis was that the load-bearing capacity would not be significantly different between the test- and the control-groups. 


\section{Material and Methods}

\subsection{Groups}

The test groups under investigation differed regarding restorative material (Table 1) and thickness of the restoration. The following materials were tested each with two different material thicknesses in groups of 10 specimens $(n=10)$ : “0.5-ZIR": 0.5 mm thick zirconia (Vita YZ HT; Vita Zahnfabrik, Bad Säckingen, Germany); "1.0-ZIR”: 1.0 mm thick zirconia (Vita YZ HT; Vita Zahnfabrik); "0.5-LDC”: 0.5 $\mathrm{mm}$ thick lithium disilicate ceramic (IPS e.max Press; Ivoclar Vivadent, Schaan, Liechtenstein); "1.0LDC": $1.0 \mathrm{~mm}$ thick lithium disilicate ceramic (IPS e.max Press); "0.5-HYC": $0.5 \mathrm{~mm}$ thick PICN (Vita Enamic; Vita Zahnfabrik); "1.0-HYC": 1.0 mm thick PICN (Vita Enamic; Vita Zahnfabrik); "0.5-COC”: $0.5 \mathrm{~mm}$ thick tooth shaded resin composite (Lava Ultimate; 3M ESPE, Seefeld, Germany) and "1.0COC": $1.0 \mathrm{~mm}$ thick tooth shaded resin composite (Lava Ultimate). Two groups of 10 specimens each were used as controls and exhibited conventional crown preparations. In one group the crowns were made of lithium-disilicate ceramic ("CLD": IPS e.max CAD; Ivoclar Vivadent) and the other group consisted of porcelain-fused to metal crowns ("PFM": Creation by Willy Geller; Manufacturer Klema, Meiningen, Austria / Esteticor Special; Cendres Metaux, Biel, Switzerland).

\subsection{Specimen preparation}

In total, one hundred extracted intact human molars were embedded in a self-curing resin (Dura Lay; Reliance Dental Manufacturing LLC, Worth, IL, USA) inside a hollow cylinder made of acrylic glass. In 80 human molars enamel was occlusally removed without extending into the dentin in order to mimic substance defects caused by attrition (Figure 1). Sharp edges were rounded off. For the two control groups, 10 specimens in each group were prepared according to conventional crown preparation guidelines: circular butt joint margins of $0.8-1.0 \mathrm{~mm}$ width, a tapering angle of $10-12$ degrees, an occlusal reduction of $1.3-1.8 \mathrm{~mm}$ and a minimal abutment height of $3.0-4.0 \mathrm{~mm}$ (Figure 1). During study procedures, all specimens were stored in water. 


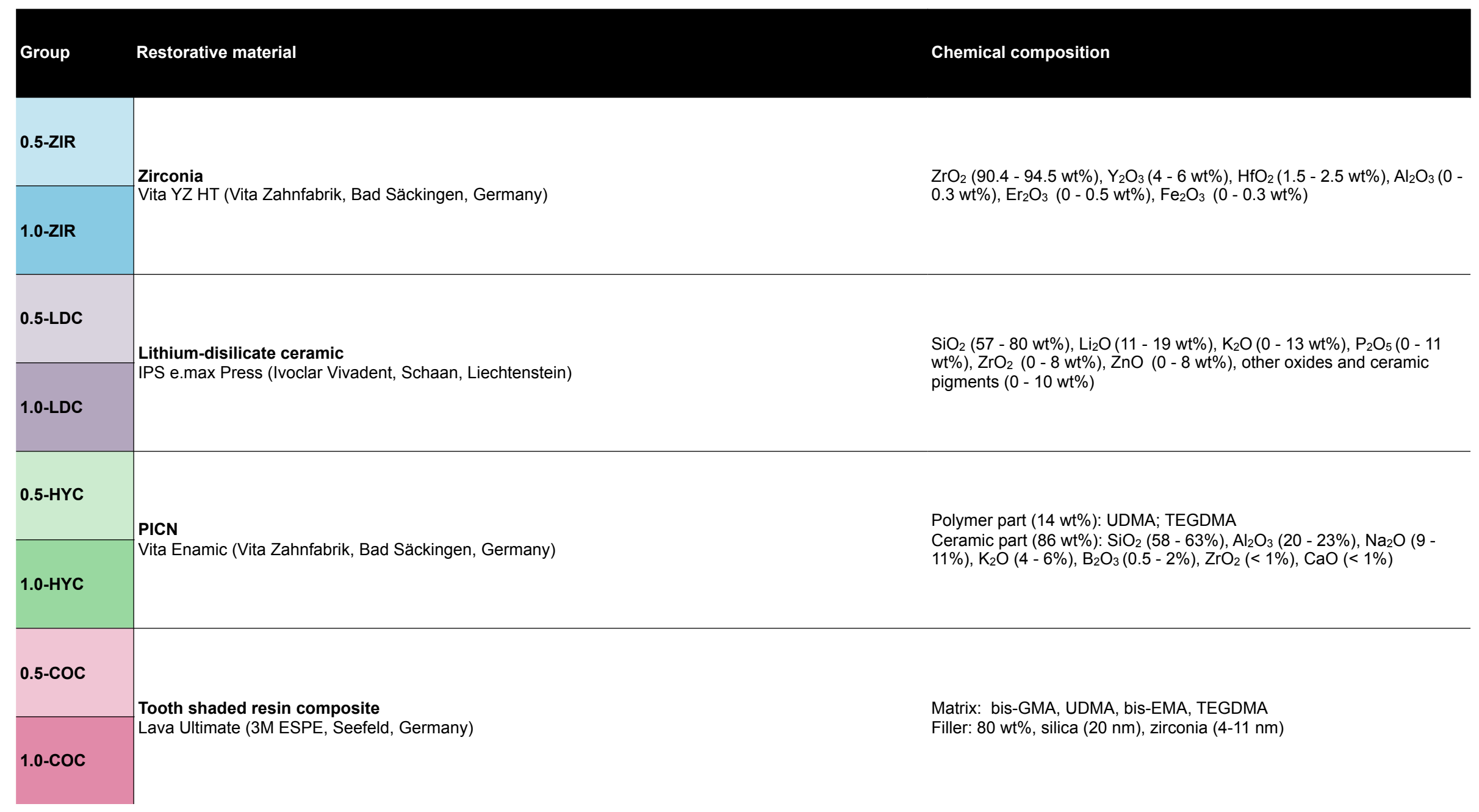

Table 1: Restorative materials of the test groups and the respective chemical composition. 


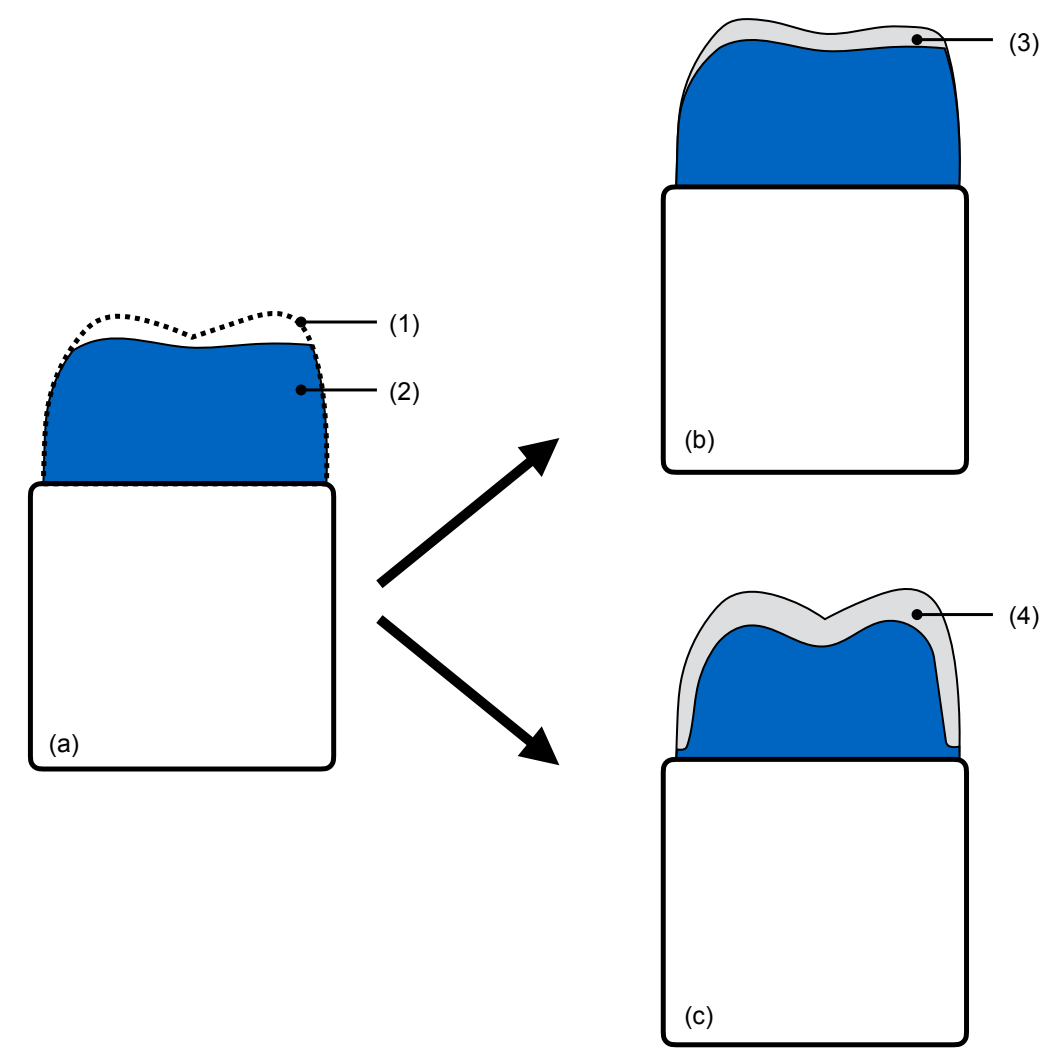

Figure 1: Schematic drawing of the embedded specimen (a) with the outline of the native tooth before preparation (1) and the remaining tooth after preparation (2). The restorations in the test group (b) consisted of a 0.5 or $1.0 \mathrm{~mm}$ thick table top (3). The control group (c) consisted of conventional crowns (4). 


\subsubsection{Test groups: scanning procedures, restoration design and fabrication}

The prepared teeth were placed in a specimen holder with acrylic teeth as reference structures (Figure 2) and scanned using an intraoral scanner (Cerec Omnicam; Software-Version 4.4, Sirona, Bensheim, Germany). Based on the resulting digital data set minimal-invasive restorations were designed (InLab, Sirona). Two different thicknesses were chosen for the restorations standardized to $0.5 \mathrm{~mm}$ (range 0.3 - $0.7 \mathrm{~mm}$ ) or $1.0 \mathrm{~mm}$ (range $0.8-1.2 \mathrm{~mm}$ ). In order to standardize this restoration thickness, the specimens were scanned (Figure 2). For each of the two groups of thicknesses an additional scan was performed. For the group with the specimen thickness of $0.5 \mathrm{~mm}$ the prepared tooth was again scanned in a $0.5 \mathrm{~mm}$ infraposition. For the other group this procedure was done with a $1.0 \mathrm{~mm}$ infraposition. The difference between the initial scan and the scan in infraposition served as the source information for the software to design the experimental reconstructions. The design software allowed the first scan to be the template for the restoration-design.

Three out of the 4 test-materials (groups $0.5-\mathrm{ZIR}, 1.0-\mathrm{ZIR}, 0.5-\mathrm{HYC}, 1.0-\mathrm{HYC}, 0.5-\mathrm{COC}, 1.0-\mathrm{COC}$ ) were directly milled out of pre-fabricated ingots by means of a 5-axis milling machine (MC X5; Sirona). For the groups $0.5-\mathrm{LDC}$ and $1.0-\mathrm{LDC}$, a template for the prospective restoration was milled out of an acrylate polymer (Vita CAD Waxx, Vita Zahnfabrik, Bad Säckingen, Germany). This template was used for the conventional "lost-wax and press technique" for the fabrication of pressed lithium-disilicate restorations. For this purpose, the acrylate polymer template was vested (IPS PressVest Premium; Ivoclar Vivadent). Subsequently, the polymer was heated to complete dissolution and the lithium disilicate ingot (IPS e.max Press; Ivoclar Vivadent) was heat pressed into the resulting void and carefully devested after cooling. 
First scan

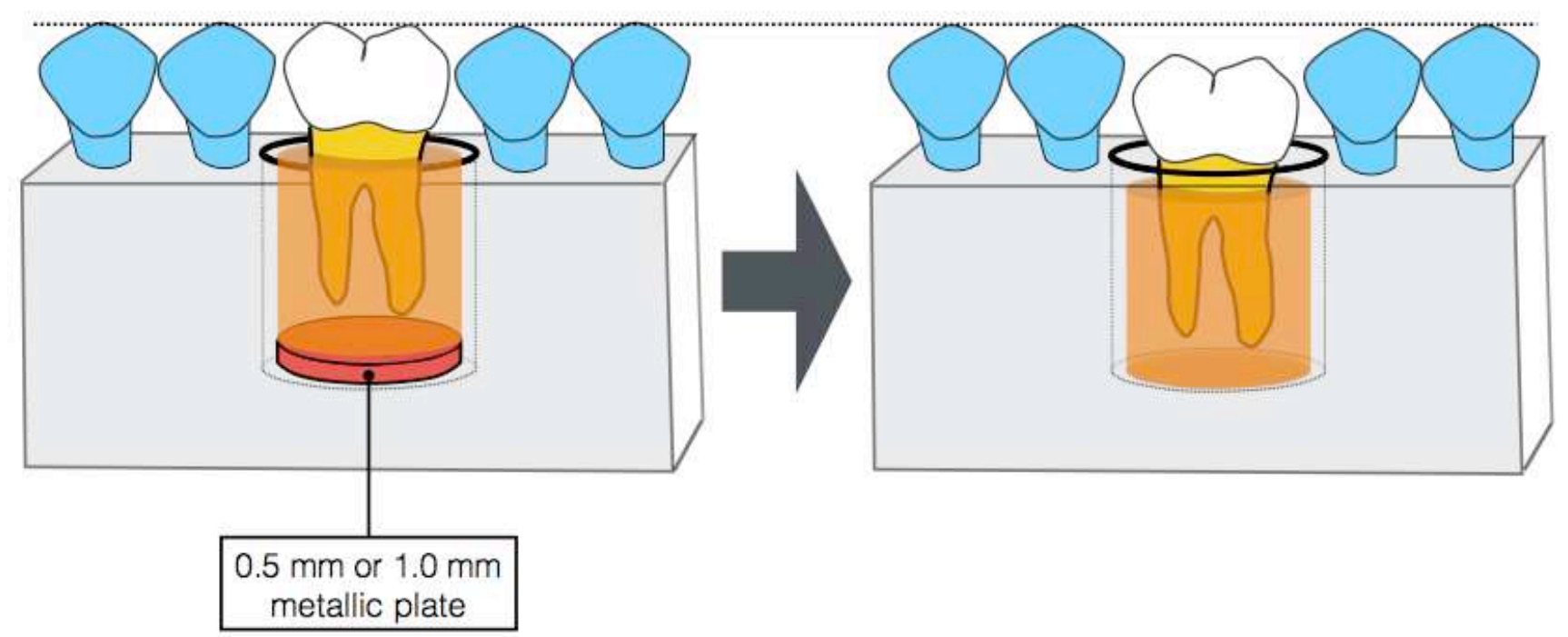

Figure 2: Presentation of the devices for the scanning procedures with the specimen holder, the embedded specimen and the $0.5 \mathrm{~mm}$ thick metal plates. The scans were performed twice: first a preparation scan was performed and secondly a reference scan on which the specimen was vertically in a 0.5 or $1.0 \mathrm{~mm}$ higher position than in the preparation scan. 


\subsubsection{Control group CLD: scanning procedures, restoration design and fabrication}

The preparations were digitized with an intraoral scanner (Cerec Omnicam; Software-Version 4.4, Sirona, Bensheim, Germany) and full crowns were digitally designed (Cerec Software 4.4, Sirona) with the dimensions of approximately $1.5 \mathrm{~mm}$ occlusal thickness and $0.8-1.0 \mathrm{~mm}$ radial thickness. The crowns were milled out of pre-fabricated ingots (IPS e.max CAD; Ivoclar Vivadent) by means of a 4axis milling machine (MCXL; Sirona). Subsequently, the crowns were sintered to full-density according to the manufacturer's instructions (Programat CS 2; Ivoclar Vivadent).

\subsubsection{Control group PFM: scanning procedures, restoration design and fabrication}

The preparations were digitized with an intraoral scanner (Cerec Omnicam; Software-Version 4.4, Sirona, Bensheim, Germany) and full crowns were digitally designed (Cerec Software 4.4, Sirona) with the dimensions of approximately $1.5 \mathrm{~mm}$ occlusal thickness and $0.8-1.0 \mathrm{~mm}$ radial thickness. Templates for the crowns were milled out of acrylic polymer ingots (Vita CAD Waxx; Vita Zahnfabrik) by means of a 4-axis milling machine (MCXL; Sirona). The porcelain-fused-to-metal crowns were directly manufactured on the prepared teeth, whereas the acrylic polymer templates served as guides to shape the final form of these crowns. The framework was manufactured manually (Esteticor Special; Cendres Metaux, Biel, Switzerland) and consecutively veneered (Creation by Willy Geller; Manufacturer Klema, Meiningen, Austria).

\subsection{Cementation protocols}

The cementation protocols were performed according to the manufacturer's recommendations for the materials used in the different groups (Table 2). 


\begin{tabular}{|c|c|c|c|}
\hline Group & Applications steps on the tooth & Applications steps on the restoration & Cementation \\
\hline CLD & $\begin{array}{l}\text { 1. Apply } 35 \% \text { phosphoric acid (Ultraetch; Ultradent, Utah, } \\
\text { USA) to the prepared enamel surfaces for } 30 \mathrm{~s} \text {. } \\
\text { 2. Spray the surface with water for } 30 \mathrm{~s} \text { and consecutively } \\
\text { gently air-dry. } \\
\text { 3. Apply the bonding agent (Heliobond; Ivoclar Vivadent) and } \\
\text { consecutively gently air-dry (no light-cure). }\end{array}$ & $\begin{array}{l}\text { 1. Apply } 5 \% \text { hydrofluoric acid for } 20 \mathrm{~s} \text { (Ivoclar Vivadent). } \\
\text { 2. Spryy the surface with water for } 60 \mathrm{~s} \text {. } \\
\text { 3. Apply the silane (Monobond Plus; Ivoclar Vivadent) for } 60 \mathrm{~s} \text {, before gently air-drying. } \\
\text { 4. Apply the bonding agent (Heliobond; Ivoclar Vivadent) and consecutively gently air-dry } \\
\text { (no light-cure). }\end{array}$ & $\begin{array}{l}\text { 1. Apply the adhesive cement, mix 1:1 (Variolink II; Ivoclar Vivadent) on the restoration. } \\
\text { 2. Remove excess cement carefully before light-curing for } 6 \times 40 \mathrm{~s} \text {. }\end{array}$ \\
\hline PFM & 1. Clean the surface and air-dry & 1. Clean the restoration with alcohol and air-dry. & $\begin{array}{l}\text { 1. Apply the cement (Ketac Cem; } 3 M \text { ESPE, Seefeld, Germany) on the restoration. } \\
\text { 2. Remove excess cement carefully. }\end{array}$ \\
\hline 1.0-ZIR & $\begin{array}{l}\text { 1. Apply } 35 \% \text { phosphoric acid (Ultraetch; Ultradent, Utah, } \\
\text { USA to the prepared enamel surfaces for } 30 \mathrm{~s} \text {. } \\
\text { 2. Spray the surface with water for } 30 \mathrm{~s} \text { and consecutively } \\
\text { gently air-dry. } \\
\text { 3. Mix the two agents } 1: 1 \text { (ED Primer A and B; Kuraray, } \\
\text { Tokyo, Japan) for } 3-5 \mathrm{~s} \text { and apply the mixture for } 60 \text { s on } \\
\text { the enamel, consecutively gently air-dry and light-cure for } \\
30 \text { seconds. }\end{array}$ & $\begin{array}{l}\text { 1. Air-abrade the inner surface of the tabletop (CoJet } 50 \mu \mathrm{m} 1.2 \mathrm{bar} ; 3 \mathrm{M} \mathrm{ESPE} \text { ) for } 15 \mathrm{~s} \\
\text { and consecutively gently air-dry. } \\
\text { 2. Apply the agent (Clearfil Ceramic Primer; Kuraray, Tokyo, Japan) for } 5 \mathrm{~s} \text {, consecutively } \\
\text { gently air-dry. }\end{array}$ & $\begin{array}{l}\text { 1. Mix the adhesive cement } 1: 1 \text { (Panavia 21; Kuraray) für } 20 \mathrm{~s} \text {, apply on the restoration. } \\
\text { 2. Apply and leave glycerin gel (Oxygard; Kuraray) on the edge of the restoration for } 7 \text { min } \\
\text { before removing the gel with water-spray. }\end{array}$ \\
\hline $1.0-$ LDC & $\begin{array}{l}\text { 1. Apply } 35 \% \text { phosphoric acid (Ultraetch; Ultradent, Utah, } \\
\text { USA to the prepared enamel surfaces for } 30 \mathrm{~s} \text {. } \\
\text { 2. Spray the surface with water for } 30 \mathrm{~s} \text { and consecutively } \\
\text { gently air-dry. } \\
\text { 3. Anply the bonding agent (Heliobond; Ivoclar Vivadent) and } \\
\text { consecutively gently air-dry (no light-cure). }\end{array}$ & $\begin{array}{l}\text { 1. Apply } 5 \% \text { hydrofluoric acid for } 20 \mathrm{~s} \text { (Ivoclar Vivadent). } \\
\text { 2. Spray the surface with water for } 60 \mathrm{~s} \text {. } \\
\text { 3. Apply the silane (Monobond Plus; Ivoclar Vivadent) for } 60 \mathrm{~s} \text {, before gently air-drying. } \\
\text { 4. Apply the bonding agent (Heliobond; Ivoclar Vivadent) and consecutively gently air-dry } \\
\text { (no light-cure). }\end{array}$ & $\begin{array}{l}\text { 1. Apply the adhesive cement, mix } 1: 1 \text { (Variolink II; Ivoclar Vivadent) on the restoration. } \\
\text { 2. Remove excess cement carefully before light-curing for } 6 \times 40 \mathrm{~s} \text {. }\end{array}$ \\
\hline 1.0-HYC & $\begin{array}{l}\text { 1. Apply } 35 \% \text { phosphoric acid (Ultraetch; Ultradent, Utah, } \\
\text { USA to the prepared enamel surfaces for } 30 \mathrm{~s} \text {. } \\
\text { 2. Spray the surface with water for } 30 \mathrm{~s} \text { and consecutively } \\
\text { gently air-dry. } \\
\text { 3. Apply the bonding agent (Heliobond; Ivoclar Vivadent) and } \\
\text { consecutively gently air-dry (no light-cure). }\end{array}$ & $\begin{array}{l}\text { 1. Apply } 5 \% \text { hydrofluoric acid for } 60 \mathrm{~s} \text { (Ivoclar Vivadent). } \\
\text { 2. Spray the surface with water for } 60 \mathrm{~s} \text {. } \\
\text { 3. Apply the silane (Monobond Plus; Ivoclar Vivadent) for } 60 \mathrm{~s} \text {, before gently air-drying. } \\
\text { 4. Apply the bonding agent (Heliobond; Ivoclar Vivadent) and consecutively gently air-dry } \\
\text { (no light-cure). }\end{array}$ & $\begin{array}{l}\text { 1. Apply the adhesive cement, mix 1:1 (Tetric Flow; Ivoclar Vivadent) on the restoration. } \\
\text { 2. Remove excess cement carefully before light-curing for } 6 \times 40 \mathrm{~s} \text {. }\end{array}$ \\
\hline $1.0-\mathrm{COC}$ & $\begin{array}{l}\text { 1. Apply } 35 \% \text { phosphoric acid (Ultraetch; Ultradent, Utah, } \\
\text { USA) to the prepared enamel surfaces for } 30 \mathrm{~s} \text {. } \\
\text { 2. Spray the surface with water for } 30 \mathrm{~s} \text { and consecutively } \\
\text { gently air-dry. } \\
\text { 3. Apply the bonding agent (Scotchbond Universal Adhesive; } \\
\text { 3M ESPE) on the tooth for } 20 \mathrm{~s} \text {, consecutively gently air-- } \\
\text { dry for } 5 \mathrm{~s} \text { (no light-cure). }\end{array}$ & $\begin{array}{l}\text { 1. Air-abrade the inner surface of the tabletop (CoJet } 50 \mu \mathrm{m} 1.2 \mathrm{bar} ; 3 \mathrm{M} \text { ESPE) for } 15 \mathrm{~s} \\
\text { and consecutively gently air-dry. } \\
\text { 2. Apply the bonding agent (Scotchbond Universal Adhesive; } 3 \mathrm{M} \text { ESPE) on the inner } \\
\text { surface of the table top for } 20 \mathrm{~s} \text {, consecutively gently air-dry for } 5 \mathrm{~s} \text { (no light-cure). }\end{array}$ & $\begin{array}{l}\text { 1. Apply the adhesive cement (RelyX Ultimate cement; } 3 \mathrm{M} \text { ESPE) on the restoration. } \\
\text { 2. Remove excess cement carefully and light-cure for } 3 \times 30 \mathrm{~s} \text {. }\end{array}$ \\
\hline
\end{tabular}

Table 2: Cementation protocols of the test and control groups. 


\subsection{Aging procedures}

All specimens were aged by means of thermo-cycling $\left(5-50^{\circ} \mathrm{C}\right.$, dwelling time $\left.120 \mathrm{~s}\right)$ and chewing simulation (1'200'000 cycles, $49 \mathrm{~N}$ force and $1.67 \mathrm{~Hz}$ loading frequency) in a custom-made chewing simulator as previously described (Krejci et al., 1990). A corrosion-free steel indenter with a rounded tip ( $\varnothing 8 \mathrm{~mm}$ ) was used as antagonist. The specimens were loaded in a direction axial to the plane of the occlusal surface with the vertical indenter moving of $1 \mathrm{~mm}$. In order to ensure that only integer specimens were used for further processing, all specimens were examined under a stereomicroscope at a magnification of $1.25 \times$.

\subsection{Static loading}

After the aging procedures, the control- and test-specimens were loaded until failure with static load. The fracture load was exerted using a universal testing machine (Zwick / Roell Z010; Zwick, Ulm, Germany). The occlusal surface of the specimens was positioned perpendicular to the indenter. The specimens were loaded with a crosshead speed of $1 \mathrm{~mm} / \mathrm{min}$ until fracture. The force required to crack the materials in the different groups was recorded $\left(\mathrm{F}_{\text {initial }}\right)$ and the load, which was registered as soon as fracture load decreased by $20 \%$ of the maximum load $\left(F_{\max }\right)$.

After fracture, digital photographs were taken in a direction perpendicular to the occlusal plane. The failure types were analyzed on these photographs using loupes at $2.5 \times$ magnification. Failure types were classified as follows: score $0=$ no visible fracture, score $1=$ cohesive fracture within the restoration, score 2 = cohesive fracture of the restoration and of the cement layer, score $3=$ fracture of the restoration-cement-tooth complex.

\subsection{Statistical analysis}

The metric variables were described with mean, median, standard deviations, quartiles, minimum and maximum. The categorical variables were summarized by counts and proportions of the categories. 
Because of the small samples sizes and non-normality of the data, the comparisons of the group medians of the metric variables were performed with non-parametric methods (Kruskal-Wallis test). The method of Dunn (Bonferroni) was used to adjust p-values, when multiple comparisons of two groups were made. The categorical parameters were compared applying the Chi-squares test.

The hypotheses that the medians of the variables of the test and control groups were different was investigated. The data for $0.5 \mathrm{~mm}$ and $1.0 \mathrm{~mm}$ thickness were analyzed separately. No power analysis was used for the derivation of the sample size. p-values $<0.05$ were stated as statistically significant. 


\section{Results}

No results were obtained for group $0.5-$ ZIR due to the impracticability to fabricate ultra-thin specimens.

\subsection{Fatigue resistance}

All specimens in all groups endured the thermo-mechanical loading without fractures, chippings or cracks.

\subsection{Load-bearing capacity}

\subsubsection{Control groups}

The control group CLD showed a median (and first Q1 and third Q3 quartiles) fatigue resistance $F_{\text {initial }}$ in Newton of 1'499 (Q1: 1'300, Q3: 2'300) (Tab. 3, Fig. 3). For PFM the respective results were 1'700 (1'500; 2'000). For CLD the respective values for $F_{\max }$ were 2 '407 (1'670; 2'490) and for PFM they were 2’033 (1'869; 2'445) (Tab. 3, Fig. 4).

\subsubsection{Restorations with $0.5 \mathrm{~mm}$ thickness}

The median $F_{\text {initial }}$ values (and first Q1 and third Q3 quartiles) in Newton for the restoration with $0.5 \mathrm{~mm}$ thickness were highest in group 0.5-COC (median: 1'025, Q1: 400, Q3: 1,400), followed by group 0.5LDC (median: 920, Q1: 641, Q3: 1'100), and by 0.5-HYC (median: 675, Q1: 500, Q3: 1'694) (Tab. 3, Fig. 3). Using the group PFM as a control, significant different medians were found between PFM and 0.5-LDC as well as between PFM and 0.5-HYC (KW: $p=0.0101)$. No differences of the medians were found when using CLD as the control (KW: $p=0.0909)$.

The median $F_{\max }$ values (and first Q1 and third quartiles Q3) in Newton were highest in group 0.5-HYC (median: 2'390, Q1: 1'355, Q2: 2'490). A bit lower values were found in group 0.5-COC (median: 2'200, Q1: 1'217, Q3: 2'492). The respective lowest $F_{\max }$ values were obtained in group 0.5-LDC (median: 1'692, Q1: 1'324, Q3: 2'355). None of the test group medians differed among each other or in 
comparison with the control groups applying the Kruskal-Wallis test (PFM as control: $p=0.6986$; CLD as control: $p=0.6952)$.

\subsubsection{Restorations with $1.0 \mathrm{~mm}$ thickness}

Regarding the $1.0 \mathrm{~mm}$ thick restorations, the following median (and first Q1a and third Q3 quartiles) for the $F_{\text {initial }}$ values in Newton were found in decreasing order: 1.0-ZIR (median: 1'950, Q1: 1'500, Q3: 2,100), 1.0-COC (median: 1'750, Q1: 850, Q3: 2'000), 1.0-HYC (median: 1'350, Q1: 1'100, Q3: 1'700) and 1.0-LDC (median: 1'150, Q1: 900, Q3: 1'300) (Table 3, Figure 3). When using the group PFM as the control, significant different medians were found between PFM and 1.0-LDC as well as between PFM and 1.0-ZIR $(K W: p=0.0140)$. No differences were found when using CLD as the control $(K W: p$ $=0.0641)$.

Group 1.0-COC revealed the highest median $F_{\max }$ values (and first Q1 and third Q3 quartiles) in Newton (median: 2'489, Q1: 2'426: Q3: 2'491), followed by 1.0-ZIR (median: 2'299, Q1: 2'156, Q3: 2'490), 1.0HYC (median: 2'124, Q1: 1'245, Q3: 2'491), and 1.0-LDC (median: 1,537, Q1: 1'245, Q3: 1'783) (Table 3, Figure 4). When comparing the test groups with either CLD or with PFM as controls, statistically significant differences were found between 1.0-LDC and 1.0-ZIR as well as between 1.0-LDC and 1.0COC (both times: CLD: KW: $p=0.0209$, and with PFM: KW: $p=0.0118$ ). 


\begin{tabular}{|c|c|c|c|c|c|c|c|c|c|c|c|c|}
\hline & \multicolumn{2}{|c|}{ n group } & \multirow[t]{2}{*}{ Mean \pm SD } & \multirow[t]{2}{*}{ Q1 } & \multirow[t]{2}{*}{ Median } & \multicolumn{2}{|c|}{ Q3 Range $\min$ to $\max$} & \multirow[t]{2}{*}{ Mean \pm SD } & \multirow[t]{2}{*}{ Q1 } & \multirow[t]{2}{*}{ Median } & \multicolumn{2}{|c|}{ Q3 Range $\min$ to $\max$} \\
\hline & & & & & & & & & & & & \\
\hline \multirow{2}{*}{$\begin{array}{l}\text { control } \\
\text { groups }\end{array}$} & 10 & CLD & $1600 \pm 624$ & 1300 & 1499 & 2300 & 500 to 2400 & $2073 \pm 539$ & 1670 & 2407 & 2490 & 1067 to 2493 \\
\hline & 10 & PFM & $1750 \pm 360$ & 1500 & 1700 & 2000 & 1200 to 2400 & $2114 \pm 328$ & 1869 & 2033 & 2445 & 1580 to 2494 \\
\hline \multirow{4}{*}{$\begin{array}{l}0.5 \mathrm{~mm} \text { thick } \\
\text { restorations }\end{array}$} & & $0.5-Z I R$ & NA & & NA & & NA & NA & & NA & & NA \\
\hline & 10 & 0.5 -LDC & $908 \pm 345$ & 640 & 920 & 1100 & 420 to 1440 & $1178 \pm 588$ & 1324 & 1692 & 2355 & 850 to 2493 \\
\hline & 10 & $0.5-\mathrm{HYC}$ & $1014 \pm 830$ & 500 & 675 & 1694 & 210 to 2400 & $1952 \pm 730$ & 1355 & 2390 & 2490 & 688 to 2494 \\
\hline & 10 & $0.5-\mathrm{COC}$ & $1014 \pm 641$ & 400 & 1025 & 1400 & 150 to 1400 & $1941 \pm 631$ & 1217 & 2200 & 2492 & 1036 to 2502 \\
\hline \multirow[t]{4}{*}{$\begin{array}{l}1.0 \mathrm{~mm} \text { thick } \\
\text { restorations }\end{array}$} & 10 & $1.0-\mathrm{ZIR}$ & $1779 \pm 628$ & 1500 & 1950 & 2100 & 390 to 2500 & $2256 \pm 265$ & 2156 & 2299 & 2490 & 1805 to 2500 \\
\hline & 10 & 1.0-LDC & $1110 \pm 289$ & 900 & 1150 & 1300 & 500 to 1500 & $1530 \pm 440$ & 1245 & 1537 & 1783 & 890 to 2272 \\
\hline & 10 & 1.0-HYC & $1300 \pm 540$ & 1100 & 1350 & 1700 & 300 to 2100 & $1839 \pm 779$ & 1245 & 2124 & 2491 & 294 to 2495 \\
\hline & 10 & $1.0-\mathrm{COC}$ & $1453 \pm 624$ & 850 & 1750 & 2000 & 280 to 2000 & $2274 \pm 455$ & 2426 & 2489 & 2491 & 1190 to 2496 \\
\hline
\end{tabular}

Table 3: The force required to crack the material $\left(F_{\text {initial }}\right)$ and the load-bearing capacity $\left(F_{\text {max }}\right)$ in Newton for all groups: mean, standard deviation $(S D)$, first quartile (Q1), median, third quartile (Q3), minimum and maximum. 


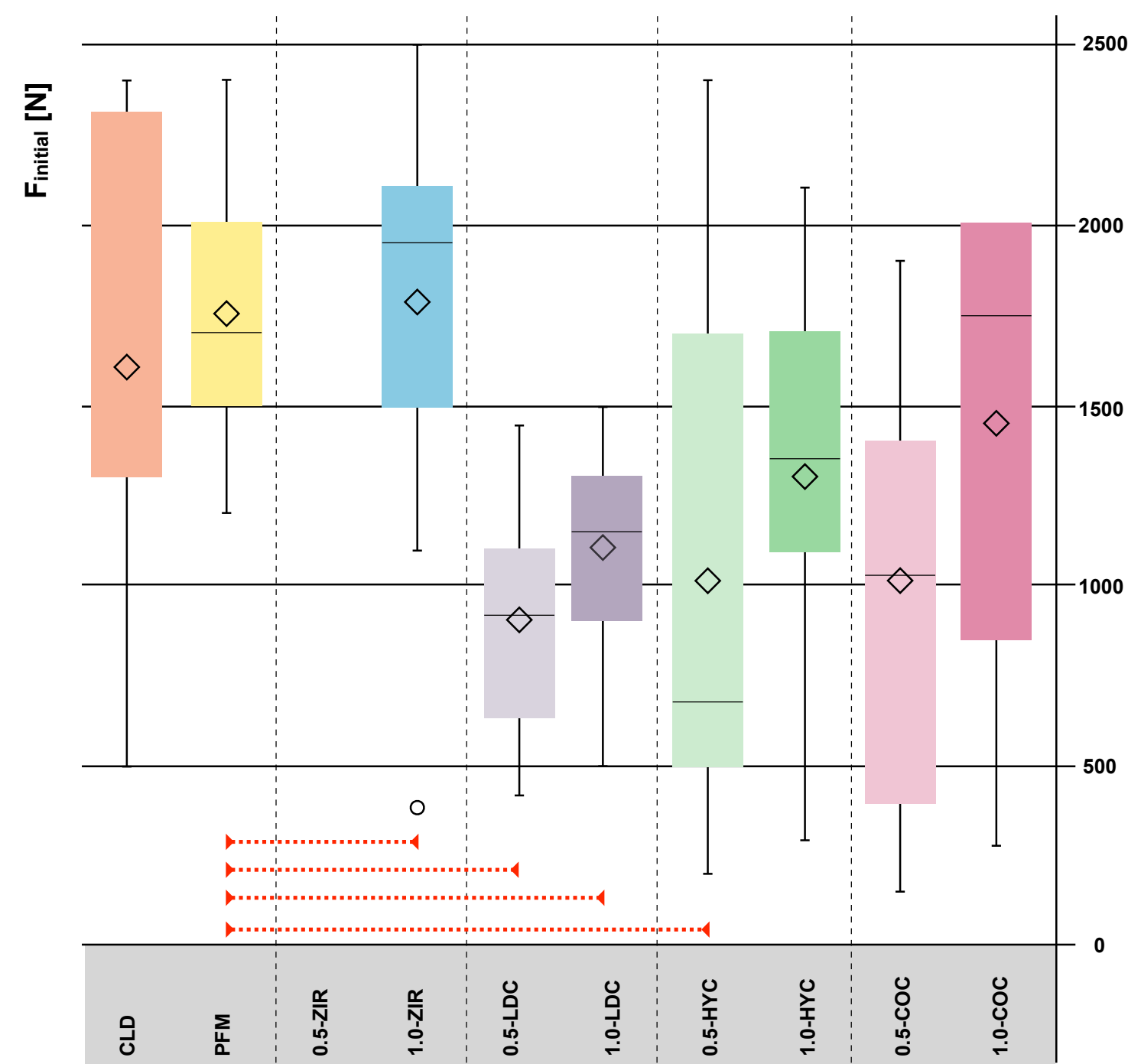

Figure 3: Box-plots for $F_{\text {initial }}$ values of the control groups CLD, PFM and the test groups 0.5-ZIR, 1.0-ZIR, 0.5-LDC, 1.0-LDC, 0.5-HYC, 1.0-HYC, 0.5-COC and 1.0-COC. Significant differences $(K W p<0.05)$ between the groups are marked with a dashed red bar 


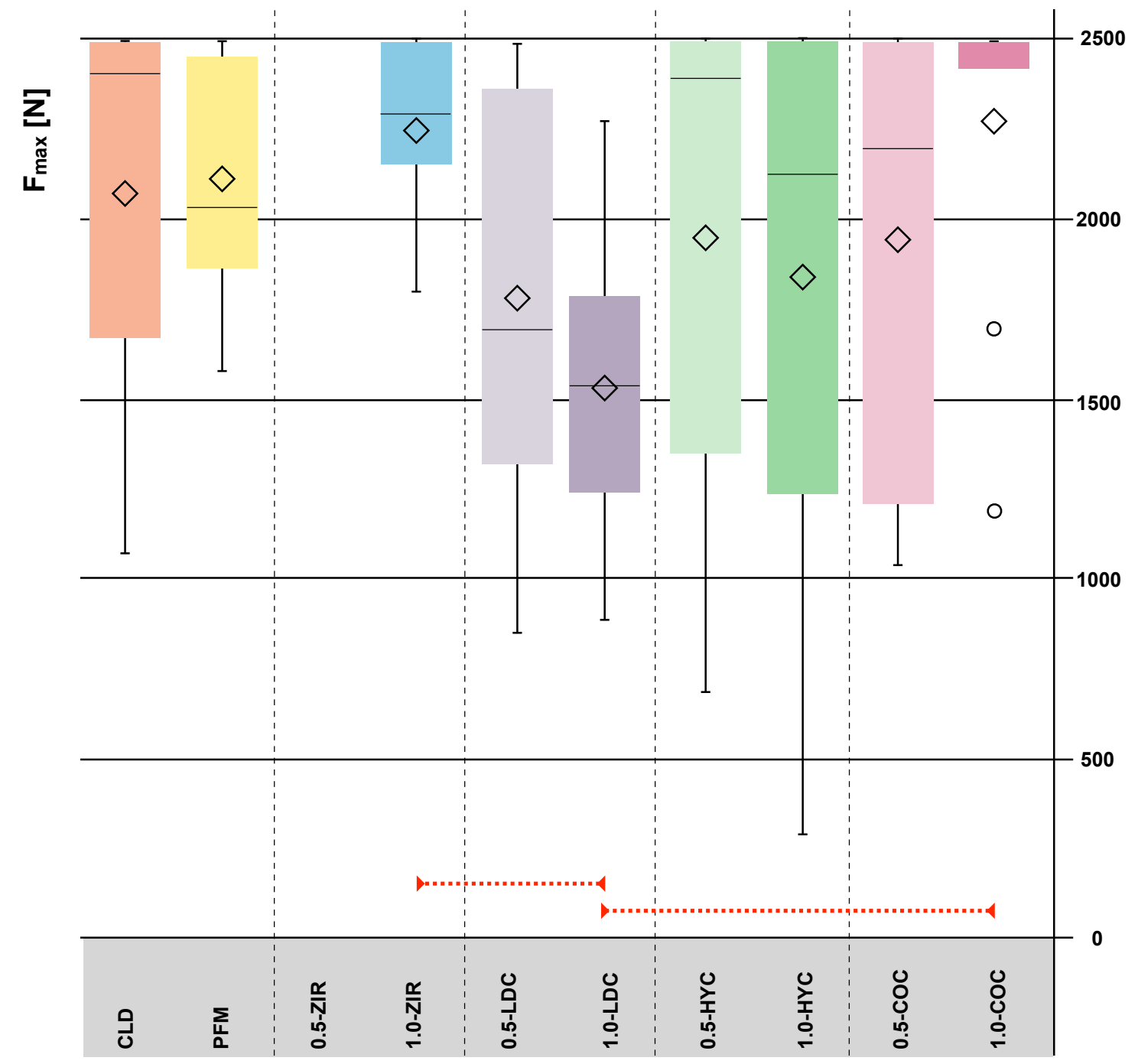

Figure 4: Box-plots for $F_{\max }$ values of the control groups CLD, PFM and the test groups 0.5-ZIR, 1.0-ZIR, 0.5-LDC, 1.0-LDC, 0.5-HYC, 1.0-HYC, 0.5-COC and 1.0-COC. Significant differences $(K W p<0.05)$ between the groups are marked with a dashed red bar. 


\subsection{Failure types}

\subsubsection{Control groups}

In the control group CLD, $80 \%$ of the fractures affected the restoration and the cement layer (score 2), while one specimen (score 0: 10\%) showed no visible fracture and one specimen fractured completely (score 3: 10\%) (Table 4). In the control group PFM, 80\% showed a score 2 fracture pattern, whereas $20 \%$ showed a score 1.

\subsubsection{Restorations with $0.5 \mathrm{~mm}$ thickness}

As the restorations for group $0.5-\mathrm{ZIR}$ could not be fabricated, no results for this group can be presented. Group 0.5-LDC primarily showed fracture scores $2(50 \%)$ and $3(40 \%)$ and only $10 \%$ score 1 fracture. The distribution for $0.5-\mathrm{HYC}$ was more wide spread with scores 0 to 3 of $3(30 \%, 10 \%, 40 \%$, and $20 \%$. The fracture modes in group $0.5-\mathrm{COC}$ were limited to scores $0(20 \%), 1(30 \%)$, and 2 (50\%). The ChiSquare-test showed no statistically significant differences when comparing the failure types of the control and test groups (Chi-squares: $p=0.0671$ ). Group 0.5-LDC, however, showed a higher incidence of score 3 failures than expected.

\subsubsection{Restorations with $1.0 \mathrm{~mm}$ thickness}

In the groups of the $1.0 \mathrm{~mm}$ thick restorations, the distributions were as follows: in group 1.0-ZIR only scores $0(20 \%)$ and $2(80 \%)$ occurred; similarly, in group 1.0-LDC only two scores were observed albeit in this group scores $2(80 \%)$ and $3(20 \%)$ (Table 4). More wide spread distributions were found in groups 1.0-HYC (score 1: $20 \%$, score 2: $30 \%$, score 3: $50 \%$ ) and 1.0-COC (score 0: $20 \%$, score 1: $10 \%$, score $2: 70 \%$ ). A statistically significant difference was revealed when comparing the test to the control groups (Chi-Square test: $\mathrm{p}=0.0062$ ). Conspicuous values were found in group 1.0-HYC, where the incidence of score 2 failures was lower and the one of score 3 failures was higher than expected. 


\begin{tabular}{|c|c|c|c|c|}
\hline Group & Score 0 [\%] & Score $1[\%]$ & Score $2[\%]$ & Score $3[\%]$ \\
\hline CLD & 10 & 0 & 80 & 10 \\
\hline PFM & 0 & 20 & 80 & 0 \\
\hline $0.5-Z I R$ & NA & NA & NA & NA \\
\hline 0.5-LDC & 0 & 10 & 50 & 40 \\
\hline 0.5-HYC & 30 & 10 & 40 & 20 \\
\hline $0.5-\mathrm{COC}$ & 20 & 30 & 50 & 0 \\
\hline 1.0-ZIR & 20 & 0 & 80 & 0 \\
\hline 1.0-LDC & 0 & 0 & 80 & 20 \\
\hline 1.0-HYC & 0 & 20 & 30 & 50 \\
\hline $1.0-\mathrm{COC}$ & 20 & 10 & 70 & 0 \\
\hline
\end{tabular}

Table 4: Distribution of failure types with percentage of no visible fracture (score 0), cohesive fracture within the restoration (score 1), cohesive fracture of the restoration and of the cement layer (score 2), fracture of the restoration-cement-tooth complex (score 3) 


\section{Discussion}

The present study revealed load-bearing capacities of the test materials to be similar to the ones of the control materials. These findings apply to both thicknesses tested, i.e. $0.5 \mathrm{~mm}$ and $1.0 \mathrm{~mm}$. This indicates that all materials tested are suitable for minimally invasive restorations in the posterior region. No complications or failures in any of the materials and thicknesses under investigation occurred during the aging phase. The investigated materials withstood static loading forces simulating clinical conditions.

That the aging procedures of the specimens did not lead to any failure of the restorations, seems to be promising for the long-term stability of the occlusal veneers. This phase followed standard procedures including thermo-cycling and chewing simulation accounting for 5 years of function (Bates et al., 1975; DeLong and Douglas, 1991; Steiner et al., 2009). Static loading led to all type of failures from no visible damage of the restoration to a complete fracture of the restoration-cement-tooth complex. Noticeable fracture patterns were found in the groups $0.5-$ LDC and 1.0-HYC with a higher incidence of score 3 failures than expected. Score 3 failures are catastrophic failures affecting the entire restoration-cementtooth complex. This failure type has been stated as characteristic for these materials (Sieper et al., 2017). Static loading forces in the present investigation went up to 2'500 N. Clinically, maximum masticatory forces in the posterior region can range from 200 to $540 \mathrm{~N}$ and reach up to $800 \mathrm{~N}$ in patients with bruxism (Bates et al., 1976). Thus, this type of catastrophic failures as a result of high loading forces can be rarely expected in a clinical setting.

Load-bearing capacities similar to the ones of the present study have been reported earlier for porcelain-fused-to-metal and lithium disilicate crowns. In one recently published study with very similar experimental conditions a high load-bearing capacity was demonstrated for lithium disilicate reinforced ceramic crowns (Sieper et al., 2017). In that study the mean fracture load after aging reached 2'648 N. In another study with a similar setup, porcelain-fused-to-metal crowns were thermo-mechanically aged and consecutively loaded until fracture. A mean fracture load of 2'000 to 2'500 N was found (Senyilmaz et al., 2010). 
In the above described study, the fracture strength of $1 \mathrm{~mm}$ thick CAD/CAM fabricated crowns made out of either lithium disilicate or PICN were tested (Sieper et al., 2017). The lithium disilicate crowns showed a mean fracture strength of 2'535 N, whereas the crowns made out of PICN revealed values of 2'128 N (Sieper et al., 2017). Another study comparing these two materials was published lately (AlAkhali et al., 2017). The study evaluated the fracture resistance of aged CAD/CAM fabricated occlusal veneers with a $0.5 / 0.8 \mathrm{~mm}$ fissure/cusp-thickness bonded to the enamel of premolars (Al-Akhali et al., 2017). A mean fracture resistance of 1'545 $\mathrm{N}$ for the lithium disilicate ceramic and 1'321 $\mathrm{N}$ for PICN specimens was found (Al-Akhali et al., 2017). As seen in the two studies, the present investigation revealed not differing load-bearing capacities comparing these two materials.

The load-bearing-capacities of occlusal veneers made out of either lithium disilicate ceramic or zirconia was tested in another study. Occlusal veneers of 0.5 or $1.0 \mathrm{~mm}$ thickness were bonded to enamel. The authors concluded that when supported by enamel, the load-bearing property of lithium disilicate occlusal veneers with a thickness of 0.6 to $1.4 \mathrm{~mm}$ can reach $75 \%$ of that of zirconia (Ma et al., 2013). In the present investigation, the $0.5 \mathrm{~mm}$ thin zirconia restorations could not be fabricated properly, thus no results were revealed and can be compared. For the $1.0 \mathrm{~mm}$ thin restorations, the ratio of $F_{\max }$ for the groups $1.0-\mathrm{LDC}$ to $1.0-\mathrm{ZIR}$ is close to $70 \%$ and therefore comparable to the findings of the stated analysis.

The authors of a previous study comparing PICN and tooth shaded resin composite as restorative materials, concluded that with a thickness of more than $0.5 \mathrm{~mm}$, a fracture resistance values above the normal bite forces can be expected (Chen et al., 2014). This is in accordance with the results derived from the present investigation. Another study comparing the fracture strength of occlusal veneers made out of these two materials, found that PICN showed significantly lower mean values than seen for the tooth shaded resin composite specimens (Egbert et al., 2015). Each study group containing 20 occlusal veneers with a central fossa thickness of $0.3 \mathrm{~mm}$ and bonded to a flat area of exposed dentin and peripheral enamel (Egbert et al., 2015). In contrast, the present study did not show significant differences in the load-bearing capacity between the two groups containing of occlusal veneers made out of PICN or tooth shaded resin composite. The difference between the outcomes, 
could be attributed to the variations in the experimental protocol in that in the Egbert et al. (2015) study the specimens were bonded to dentin, whereas in this study the substrate was enamel only. Early detachment of the restorative materials from dentin as a consequence of aging has been shown in previous studies (Montagner et al., 2014). Confining the substrate surface within enamel only in this study, most likely resulted in improved adhesion and thereby no significant differences in load-bearing capacity.

Although the load-bearing capacity of the tested materials did not show significant differences in this study settings where the strength was measured as a function of thickness, when inherent mechanical properties are considered, the tested materials show significant variations in terms of fracture strength and fracture toughness. In terms of fractural strength and fracture toughness, typically polymeric materials demonstrate lower values, whereas zirconia exhibit the highest values followed by lithiumdisilicate (Della Bona et al., 2014; Denry and Kelly, 2008; Guazzato et al., 2004a, 무; Porto et al., 2018). One can speculate that the adhesion between the tooth substance and the cementation surface of the used materials compensate for the individual inferior mechanical properties of some of the tested materials (Ozcan et al., 2005; Ozcan et al., 2007). Since the crack propagation typically initiates form the tensile surface of the bonded materials, durable adhesion and thereby the conditioning protocol dictates the longevity of adhesion and the load-bearing capacity (Zhang et al., 2009). In this context it can be anticipated that the morphology of the restoration in connection with the adhesion to the tooth surface may change the classical ranking of the materials regarding their mechanical properties. It must be noted that in this study attention was payed also to the $F_{\text {initial }}$ values. When the $F_{\text {initial }}$ results of the control groups where compared to these of PICN the latter showed significantly lower loadbearing capacity as opposed to PFM. Principally, the strength of veneering ceramic is an essential element to avoid chipping or fracture from the entire PFM reconstruction (Ozcan and Niedermeier, 2002). As the veneered part of the PFM contains feldspathic ceramic with superior mechanical properties compared to PICN (Della Bona et al., 2014), the lower values of the PICN could be attributed to the polymeric part of this hybrid material. However, this difference was not evident when the restoration thickness increased to $1 \mathrm{~mm}$. Interestingly, tooth shaded resin composite material did not 
show significant difference compared to the control groups at both thicknesses. This again clearly indicates the importance of adhesion between the tooth and the restorative material. As it has been demonstrated in previous studies adhesion of polymeric materials is superior to those of ceramic ones (Ozcan et al., 2005). This may be the explanation for the significantly higher $F_{\max }$ values of the group using the tooth shaded resin composite material when compared to the reconstructions made out of lithium disilicate ceramic.

Looking again at the $F_{\text {initial }}$ values, the 0.5 and $1.0 \mathrm{~mm}$ thick lithium disilicate restorations were significantly lower compared to the results obtained in the PFM group. It was expected that the feldspathic ceramic layer of the PFM should have revealed lower values than lithium disilicate ceramic since the latter presents enhanced mechanical properties (Guazzato et al., 2004a). In contrast, due to the favorable mechanical properties, the $F_{\text {initial }}$ values of the zirconia were indeed significantly higher than that of PFM (Guazzato et al., 2004b). Typically bi-layered ceramic structures suffer from edge chipping due to fracture of the veneering ceramic, either on the PFM (Ozcan et al., 2005) or on ceramicceramic reconstructions (Raigrodski et al., 2012). In that respect, monolithic reconstructions as in the case of zirconia and lithium disilicate, deliver more favorable outcomes which could be verified for monolithic zirconia in this investigation. 


\section{Conclusions}

Regarding their load-bearing capacity, minimally invasive occlusal veneers made of ceramic and hybrid materials can be applied to correct occlusal tooth wear and thus replace conventional crown restorations. The statistically significant differences found between different materials may be clinically irrelevant, since the mean values obtained surpassed normal force spans. 


\section{Conflict of Interest}

This study was mainly financially supported by the Clinic for Fixed and Removable Prosthodontics and Dental Material Science, Center of Dental Medicine, University of Zurich, Zurich, Switzerland. The Swiss Society for Reconstructive Dentistry (SSRD) supported this investigation in parts with a research grant. The authors acknowledge the material support from Vita Zahnfabrik, Ivoclar Vivadent and 3M ESPE. 


\section{Acknowledgements}

The authors express their special thanks to Albert Trottmann, Pascal Müller, Tonino Di Bello, Pavla Pasic and Mila Maeder for their valuable help during fabrication of the specimen. 


\section{References}

Al-Akhali, M., Chaar, M.S., Elsayed, A., Samran, A., Kern, M., 2017. Fracture resistance of ceramic and polymer-based occlusal veneer restorations. Journal of the mechanical behavior of biomedical materials 74, 245-250.

Awada, A., Nathanson, D., 2015. Mechanical properties of resin-ceramic CAD/CAM restorative materials. J. Prosthet. Dent. 114, 587-593.

Bates, J.F., Stafford, G.D., Harrison, A., 1975. Masticatory function--a review of the literature. 1. The form of the masticatory cycle. J. Oral Rehabil. 2, 281-301.

Bates, J.F., Stafford, G.D., Harrison, A., 1976. Masticatory function - a review of the literature. III. Masticatory performance and efficiency. J. Oral Rehabil. 3, 57-67.

Chen, C., Trindade, F.Z., de Jager, N., Kleverlaan, C.J., Feilzer, A.J., 2014. The fracture resistance of a CAD/CAM Resin Nano Ceramic (RNC) and a CAD ceramic at different thicknesses. Dent. Mater. 30, 954-962.

Christel, P., Meunier, A., Heller, M., Torre, J.P., Peille, C.N., 1989. Mechanical properties and shortterm in-vivo evaluation of yttrium-oxide-partially-stabilized zirconia. J. Biomed. Mater. Res. 23, 45-61.

Della Bona, A., Corazza, P.H., Zhang, Y., 2014. Characterization of a polymer-infiltrated ceramicnetwork material. Dent. Mater. 30, 564-569.

DeLong, R., Douglas, W.H., 1991. An artificial oral environment for testing dental materials. IEEE Trans. Biomed. Eng. 38, 339-345.

Denry, I., Kelly, J.R., 2008. State of the art of zirconia for dental applications. Dent. Mater. 24, 299307.

Dietschi, D., Argente, A., 2011. A comprehensive and conservative approach for the restoration of abrasion and erosion. part II: clinical procedures and case report. The European journal of esthetic dentistry : official journal of the European Academy of Esthetic Dentistry 6, 142-159.

Edelhoff, D., Sorensen, J.A., 2002a. Tooth structure removal associated with various preparation designs for anterior teeth. J. Prosthet. Dent. 87, 503-509.

Edelhoff, D., Sorensen, J.A., 2002b. Tooth structure removal associated with various preparation designs for posterior teeth. Int. J. Periodontics Restorative Dent. 22, 241-249. 
Egbert, J.S., Johnson, A.C., Tantbirojn, D., Versluis, A., 2015. Fracture strength of ultrathin occlusal veneer restorations made from CAD/CAM composite or hybrid ceramic materials. Oral Sci Int 12, 5358.

Elsaka, S.E., Elnaghy, A.M., 2016. Mechanical properties of zirconia reinforced lithium silicate glassceramic. Dent. Mater. 32, 908-914.

Guazzato, M., Albakry, M., Ringer, S.P., Swain, M.V., 2004a. Strength, fracture toughness and microstructure of a selection of all-ceramic materials. Part I. Pressable and alumina glass-infiltrated ceramics. Dent. Mater. 20, 441-448.

Guazzato, M., Albakry, M., Ringer, S.P., Swain, M.V., 2004b. Strength, fracture toughness and microstructure of a selection of all-ceramic materials. Part II. Zirconia-based dental ceramics. Dent. Mater. 20, 449-456.

Guess, P.C., Schultheis, S., Wolkewitz, M., Zhang, Y., Strub, J.R., 2013. Influence of preparation design and ceramic thicknesses on fracture resistance and failure modes of premolar partial coverage restorations. J. Prosthet. Dent. 110, 264-273.

Krejci, I., Reich, T., Lutz, F., Albertoni, M., 1990. [An in vitro test procedure for evaluating dental restoration systems. 1. A computer-controlled mastication simulator]. Schweiz. Monatsschr. Zahnmed. $100,953-960$.

Loomans, B., Opdam, N., Attin, T., Bartlett, D., Edelhoff, D., Frankenberger, R., Benic, G., Ramseyer, S., Wetselaar, P., Sterenborg, B., Hickel, R., Pallesen, U., Mehta, S., Banerji, S., Lussi, A., Wilson, N., 2017. Severe Tooth Wear: European Consensus Statement on Management Guidelines. J. Adhes. Dent. 19, 111-119.

Ma, L., Guess, P.C., Zhang, Y., 2013. Load-bearing properties of minimal-invasive monolithic lithium disilicate and zirconia occlusal onlays: finite element and theoretical analyses. Dent. Mater. 29, 742751.

Miyazaki, T., Nakamura, T., Matsumura, H., Ban, S., Kobayashi, T., 2013. Current status of zirconia restoration. J Prosthodont Res 57, 236-261.

Montagner, A.F., Sarkis-Onofre, R., Pereira-Cenci, T., Cenci, M.S., 2014. MMP Inhibitors on Dentin Stability: A Systematic Review and Meta-analysis. J. Dent. Res. 93, 733-743.

Muts, E.J., van Pelt, H., Edelhoff, D., Krejci, I., Cune, M., 2014. Tooth wear: a systematic review of treatment options. J. Prosthet. Dent. 112, 752-759.

Ozcan, M., Alander, P., Vallittu, P.K., Huysmans, M.C., Kalk, W., 2005. Effect of three surface conditioning methods to improve bond strength of particulate filler resin composites. J Mater Sci Mater Med 16, 21-27. 
Ozcan, M., Barbosa, S.H., Melo, R.M., Galhano, G.A., Bottino, M.A., 2007. Effect of surface conditioning methods on the microtensile bond strength of resin composite to composite after aging conditions. Dent. Mater. 23, 1276-1282.

Ozcan, M., Niedermeier, W., 2002. Clinical study on the reasons for and location of failures of metalceramic restorations and survival of repairs. Int. J. Prosthodont. 15, 299-302.

Porto, T.S., Roperto, R.C., Akkus, A., Akkus, O., Teich, S., Faddoul, F.F., Porto-Neto, S.T., Campos, E.A., 2018. Effect of thermal cycling on fracture toughness of CAD/CAM materials. Am. J. Dent. 31, 205-210.

Raigrodski, A.J., Hillstead, M.B., Meng, G.K., Chung, K.H., 2012. Survival and complications of zirconia-based fixed dental prostheses: a systematic review. J. Prosthet. Dent. 107, 170-177.

Senyilmaz, D.P., Canay, S., Heydecke, G., Strub, J.R., 2010. Influence of thermomechanical fatigue loading on the fracture resistance of all-ceramic posterior crowns. Eur. J. Prosthodont. Restor. Dent. $18,50-54$.

Sieper, K., Wille, S., Kern, M., 2017. Fracture strength of lithium disilicate crowns compared to polymer-infiltrated ceramic-network and zirconia reinforced lithium silicate crowns. Journal of the mechanical behavior of biomedical materials 74, 342-348.

Smith, B.G., Knight, J.K., 1984. A comparison of patterns of tooth wear with aetiological factors. Br. Dent. J. 157, 16-19.

Steiner, M., Mitsias, M.E., Ludwig, K., Kern, M., 2009. In vitro evaluation of a mechanical testing chewing simulator. Dent. Mater. 25, 494-499.

Swain, M.V., Coldea, A., Bilkhair, A., Guess, P.C., 2016. Interpenetrating network ceramic-resin composite dental restorative materials. Dent. Mater. 32, 34-42.

Wagner, W.C., Chu, T.M., 1996. Biaxial flexural strength and indentation fracture toughness of three new dental core ceramics. J. Prosthet. Dent. 76, 140-144.

Zhang, Y., Kim, J.W., Bhowmick, S., Thompson, V.P., Rekow, E.D., 2009. Competition of fracture mechanisms in monolithic dental ceramics: flat model systems. Journal of biomedical materials research. Part B, Applied biomaterials 88, 402-411. 